\title{
Model test study of bending moment and negative skin friction for batter rock-socketed piles under surface load
}

\author{
Guo Wei ${ }^{1}$, Zhuang Daokun ${ }^{1}$, Ren Yuxiao*1, Cui Wenxi ${ }^{1}$, Yue Changxi ${ }^{2,3}$, Yu Changyi ${ }^{2,3}$ \\ ${ }^{1}$ School of Civil Engineering, Tianjin University, Tianjin 300350, China \\ ${ }^{2}$ Key Laboratory of Port Geotechnical Engineering of Tianjin, Tianjin 300222, China \\ ${ }^{3}$ CCCC Tianjin Port Engineering Institute Co., Ltd. Tianjin 300222, China
}

\begin{abstract}
Batter rock-socketed piles (BRSP) foundation is one of common foundations, such as port engineering or cross-sea bridge, while there are few studies on negative skin friction for BRSP. A series of model tests are conducted to explore negative skin friction of BRSP which are embedded in thick soft clay. The effects of the inclined angle of piles and soil consolidation time to negative friction resistance and the bending moment of BRSP are analyzed. The test results show that: the development of negative friction and bending moment BRSP have pronounced time effect; the longer the consolidation time is, the slower the axial force and bending moment intensify. The ultimate pile shaft axial force and bending moment increases nonlinearly concerning the inclined angle of piles. And the "neutral point" position and peak point of bending moment is always located at $0.9 \sim 1.0$ times soil depth.
\end{abstract}

\section{Introduction}

Batter rock-socketed piles (BRSP) have been widely used in port engineering, cross-sea bridge, offshore wind power foundation, and other offshore projects due to their excellent horizontal bearing capacity. The offshore area usually has thick clay layers, and the application of additional load ${ }^{[1-3]}$ will cause soil settlement and soil re-consolidation. Negative friction resistance and bending moment generated by soil settlement in soil layer and surface load will affect the stability of pile foundation and bring hidden trouble to engineering construction.

Studies on negative friction resistance of vertical piles show that consolidation and settlement of soil layer takes a long time. Hence, the development of negative friction resistance has noticeable time effect ${ }^{[4]}$. The consolidation and settlement time of deep soft soil is very long. Although more reliable experimental data can be obtained by monitoring the generation and development of pile body friction resistance through field tests ${ }^{[2-3]}$, the vast time and property costs make it difficult to set up a control group for comparative analysis.

Therefore, the model test is a commonly used research method. To enhance the performance effect of negative friction resistance in model test, soil settlement can be accelerated and increased using surface load ${ }^{[4-6]}$, jack loading ${ }^{[7-8]}$, air pressure loading ${ }^{[9-10]}$, and vacuum preloading ${ }^{[11]}$. The rise of soil settlement will lead to the increase of negative friction resistance and the upward shift of neutral point, but there is a maximum value of soil settlement, which makes negative friction resistance fully effective ${ }^{[8]}$. Studies on negative friction resistance of pile groups show that pile groups have a "shielding effect" when pile spacing is less than $5 \mathrm{D}^{[9]}$.

Compared with vertical piles, there are few studies on negative friction resistance of inclined piles. Due to the existence of inclined angle of inclined piles, it is more difficult to load the surrounding soil layer. Both air pressure loading ${ }^{[19]}$ and steel ball loading ${ }^{[13]}$ have their limitations. In addition to the influence of negative friction resistance on the bearing capacity of pile foundation, the bending moment of pile shafts is also the critical point to be considered in the design of inclined piles. During the consolidation process of soil around the pile, bending moment of batter piles will gradually increase with time and reach a stable value ${ }^{[6,9]}$.

Based on the above reasons, a series of model tests are conducted to explore negative skin friction of batter rock-socketed piles embedded in thick soft clay. The changes of negative friction, axial force and bending moment of rock-socketed inclined piles with different inclination angles are analyzed under the condition of consolidation and settlement of soil surface under surcharge load. The position depth of neutral point and the maximum point of bending moment are analyzed. The influence of dip angle on load transfer law of pile is studied.

\section{Model test}

\subsection{Test device and process}

Fig. 1 is the schematic diagram of the experimental device, mainly including the test chamber, model pile,

\footnotetext{
* Corresponding author: renyx66@163.com
} 
load block, soil pressure sensor, settlement marker, and dial indicator, etc. The size of the test chamber (length $\times$ width $\times$ height) is $800 \mathrm{~mm} \times 800 \mathrm{~mm} \times 800 \mathrm{~mm}$, and the surrounding area is composed of $15 \mathrm{~mm}$ thick tempered glass. Firstly, the model piles are fixed in the corresponding position according to the required inclination angle and depth. Considering that the optimal rock-socketed depth is $4 \mathrm{D}$. In order to eliminate the shielding effect of pile groups, the spacing at any place of pile body is greater than $6 \mathrm{D}$. The fixing column of the piezometer and the stratified settlement marker is fixed on the steel frame vertically. A $20 \mathrm{~cm}$ thick concrete layer is poured to simulate rock. Cured for 7 days to make the concrete layer completely hardened. Fix the hole manometer at the appropriate depth. Then soft clay with a thickness of $50 \mathrm{~cm}$ is filled into the test chamber. The soft clay layer is successively covered with a $70 \mathrm{~mm}$ thick layer of saturated fine sand, geotextile and a $20 \mathrm{~mm}$ thick bearing plate. Overburden load is uniformly applied on the bearing plate at one time, and the sum of overburden load above the clay layer is calculated to be $4.7 \mathrm{kPa}$.

The micro-strain of the pile is measured by the strain gauge, and then recorded in real-time by the data acquisition and processing system (model: DH3816N Static Strain Test System). The settlement of the soil layer is measured by settlement marker and dial meter. SS is the stratified settlement scale, taking the top of clay surface as 0 points, and the layout depth is $0 \mathrm{~m},-0.2 \mathrm{~m}$ and, $-0.4 \mathrm{~m}$, respectively. The super pore pressure in the soil layer is measured by the soil pressure gauge (model: JTM-V3000A), PW is the pore pressure gauge, and the layout depth is $-0.1 \mathrm{~m},-0.3 \mathrm{~m}$ ands, $0.5 \mathrm{~m}$ respectively.

After the test chamber is laid out, the test chamber is left standing for two days, and the dial gauge, pore pressure gauge, and strain gauge are recorded continuously until the soil settlement no longer changes, which means the test is over.

\subsection{Parameters of model pile}

In the test, plexiglass tubes with an outer diameter of $30 \mathrm{~mm}$ and $40 \mathrm{~mm}$ and a wall thickness of $2 \mathrm{~mm}$ are used as the model pile, and their elastic modulus is measured at 2.8GPa. Before making the model pile, the plexiglass tube is first divided into two halves along the longitudinal axis, and 7 pairs of strain gages are symmetrically attached to the pile body. The decorate of strain gages is shown in Fig. 1(a). Then the pile pipe is re-bonded and anti-seepage treatment is performed, as shown in Fig. 1(b). Next, fine sand (particle size at $1 \mathrm{~mm}$ ) is glued on the outside of the pile to increase the pile shafts roughness, and the actual average pile diameters are about $32 \mathrm{~mm}$ and $42 \mathrm{~mm}$. According to the interface shear test, the pile-clay friction coefficient $\tan \varphi$ is measured to be about $0.59^{[8]}$.

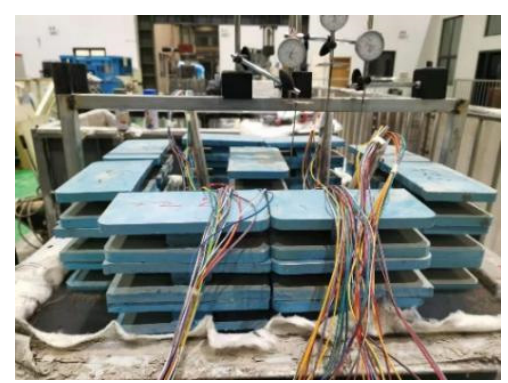

(a) Test chamber

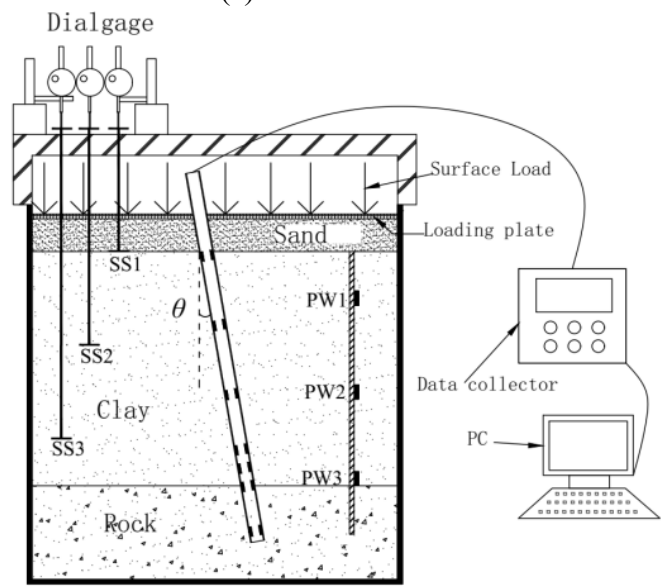

(b) Schematic diagram

Fig.1 Model test device diagram

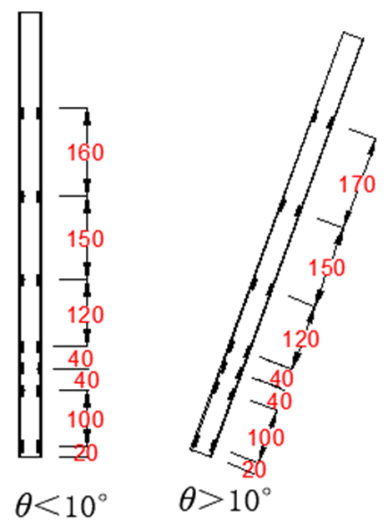

Fig.2 Strain gage arrangement

\subsection{Selection of soil (rock) around the test pile}

The surrounding soil of the test pile is filled with soft soil from a construction site in Dongjiang Port of Tianjin Binhai New Area, which is always soaked in water after being retrieved.

When preparing soil sample, add water and stir it evenly before pouring it into the test chamber. In this test, self-allocated concrete is used to simulate the bedrock at the bottom of pile. The rock ratio is sand: quick-setting cement: gypsum: water $=450: 100: 27: 70$. The specific parameters of clay and rock measured are shown in Table 1. 
Table 1 Physical and mechanical parameters of clay

\begin{tabular}{cccccc}
\hline & $\begin{array}{c}\text { Density } \\
\rho \\
\mathrm{kg} / \mathrm{m}^{3}\end{array}$ & $\begin{array}{c}\text { Water } \\
\text { Content } \\
\omega / \%\end{array}$ & $\begin{array}{c}\text { Poisson's Ratio } \\
v\end{array}$ & $\begin{array}{c}\text { Plasticity } \\
\text { Index } \\
I_{\mathrm{p}}\end{array}$ & $\begin{array}{c}\text { UCS } \\
\sigma_{\mathrm{c}} / \mathrm{MPa}\end{array}$ \\
\hline Clay & 1618 & 55 & 0.4 & 21 & - \\
\hline Rock & 2210 & - & 0.2 & - & 6.5 \\
\hline
\end{tabular}

\subsection{Test scheme}

The model test aims to reveal the influence law of soil consolidation and settlement on inclined piles with different inclination angles in deep soil with overburden, and to summarize the rules of bending moment and negative friction resistance of piles influenced by consolidation time and inclination angle. Piles P1 P3 are arranged in the test chamber, and the soil in the chamber is loaded by iron block. The detailed test conditions are shown in Table 2.

Table 2 Test plan

\begin{tabular}{rcccc}
\hline & $\begin{array}{c}\text { Number of } \\
\text { pile }\end{array}$ & $\begin{array}{c}\text { Diameter } \\
\mathrm{D} / \mathrm{mm}\end{array}$ & $\begin{array}{c}\text { Dip angle } \\
/ \mathrm{o}\end{array}$ & $\begin{array}{c}\text { Pile length } \\
\mathrm{L} / \mathrm{mm}\end{array}$ \\
\hline $\mathrm{P} 0=4.7$ & $\mathrm{P} 1$ & 32 & 0 & 700 \\
$\mathrm{nyy}$ & $\mathrm{P} 2$ & 32 & 7 & 705 \\
\cline { 2 - 5 } & $\mathrm{P} 3$ & 32 & 17 & 732 \\
\hline
\end{tabular}

\section{Analysis of model test results}

\subsection{Analysis of soil settlement and excess pore pressure}

The settlement of soil layer and super pore pressure in soil were measured continuously by stratified settlement marker and pore pressure gauge. As shown in Fig. 3 and 4 , the super pore pressure dissipates, and the settlement of the soil layer gradually increased with the increase of consolidation time. The rate slowed down to steady gradually. The stabilization time of the soil layer settlement was 25 days. After the consolidation of soil layer is completed, the settlement of the soil surface in the test chamber is $10.8 \mathrm{~mm}$.

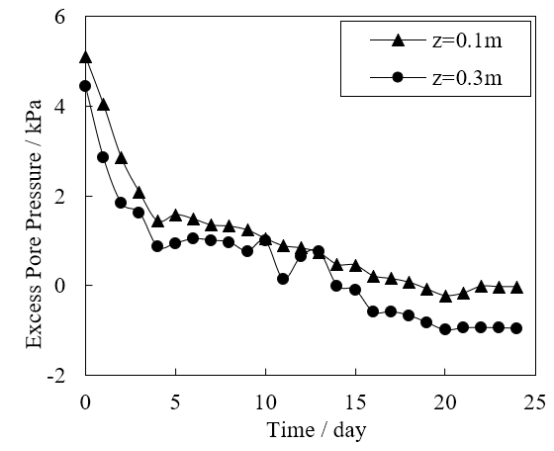

Fig.3 The excess pore pressure dissipates with time

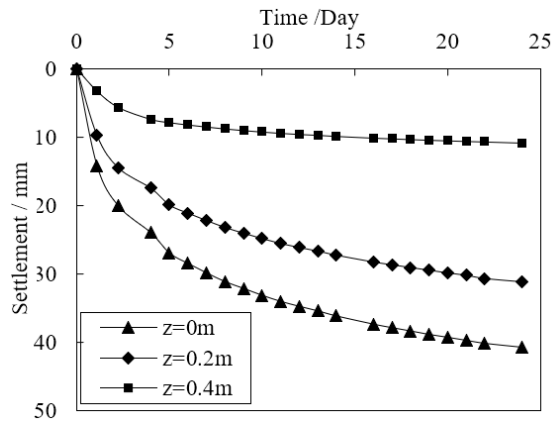

Fig.4 The soil subsided with time

\subsection{Analysis of the influence of time and inclination angle on pile axial force and negative friction resistance}

The contact point between the pile and the soil surface is taken as zero, and the axial force of the pile at this point is considered zero. The pile axial force is derived from the negative friction resistance of the pile side.

As can be seen from Fig.5, when the soil is loaded on the surface, the development trend of the extreme point of negative friction resistance on the pile body is roughly the same as soil settlement, and the development speed in the early stage is faster than that in the later stage. The axial force of pile shafts increases with the addition of inclination angle in the same consolidation time, as well as the negative friction resistance.

Fig. 6 shows that in the consolidation process of the soil layer, pile axial force gradually develops with the increase of consolidation time.

And the maximum point of axial force, namely the neutral point, is always located at the rock-soil interface. The overall settlement of the soil is larger when there is a load on its surface, and the pile compression is always smaller than the settlement of the soil. Therefore, the pile in the soil section is constantly subjected to negative friction resistance. There is no consolidation and settlement in the rock layer, so the pile at the rock layer is subjected to positive friction resistance, and the pile shaft axial force decreases with depth.

At the same time, it can be seen that negative friction resistance of the rock-socketed pile gradually increases with the addition of its inclination angle. The calculated pile length and the soil pressure around the pile increase with the addition of the inclination angle, thus causing the augment of the negative friction resistance of the pile body.

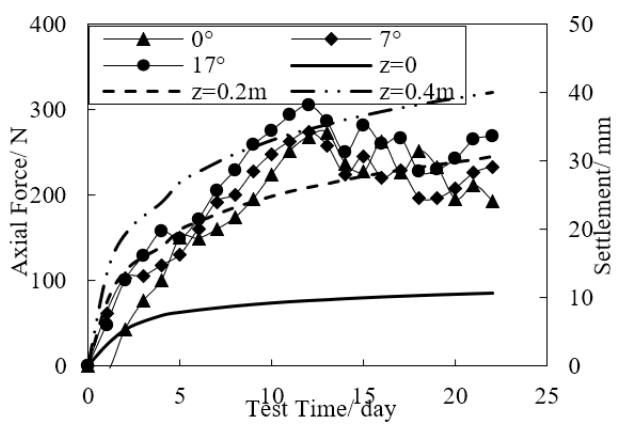

Fig.5 The maximum value of axial force changes with time 


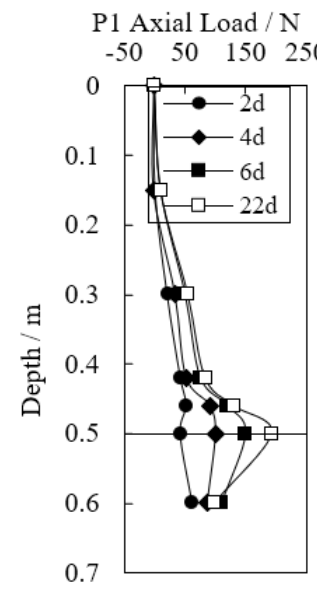

(a) $\theta=0^{\circ}$

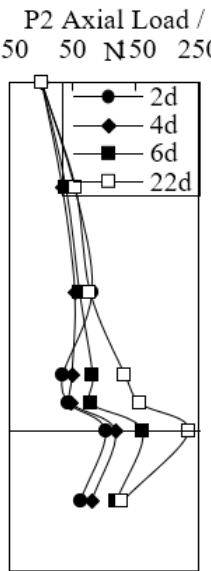

(b) $\theta=7^{\circ}$
P3 Axial Load / N $\begin{array}{llll}-50 & 50 & 150 & 250350\end{array}$

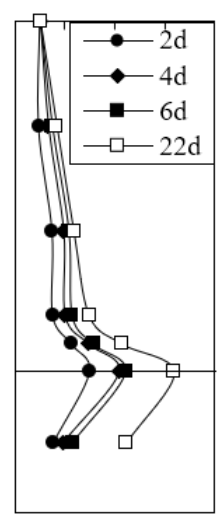

(c) $\theta=17^{\circ}$
Fig.6 Pile axial force distribution changes with time

\subsection{Analysis of the influence of time and inclination Angle on bending moment of pile shaft}

The contact point between the pile and the soil surface is taken as zero, and the bending moment at this point is zero. Below this point, the pile is subjected to friction resistance. When the soil is loaded on the surface, the pile bending moment mainly dues to soil settlement.

According to Fig. 7, the variation trend of peak bending moment of pile body in different periods is highly similar to the trend of soil settlement. The development speed in the early stage is faster than that in the later stage.

Fig. 8 shows that for piles with the same angle, the bending moment of the pile body gradually increases with the accumulation of consolidation time. It is mainly because with the accumulation of consolidation time of soil layer, soil settlement and negative friction gradually increase and the "pull-down" effect on the pile is more prominent. Hence, the bending moment of the pile increases gradually.

Under the same consolidation time and soil settlement, the bending moment of the rock-socketed pile increases gradually with the addition of its inclination angle. It is because with the addition of inclination angle, the overlying soil weight of piles and the component of soil settlement in the radial direction of piles gradually increase, and the "downward" effect on pile is more obvious, thus increasing the bending moment of pile body.

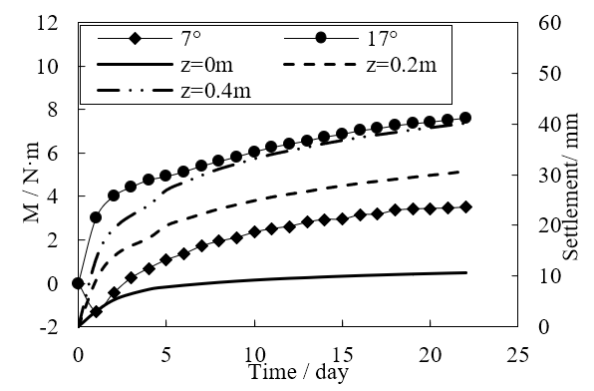

Fig. 7 Change diagram of the maximum value of bending moment of pile body with time

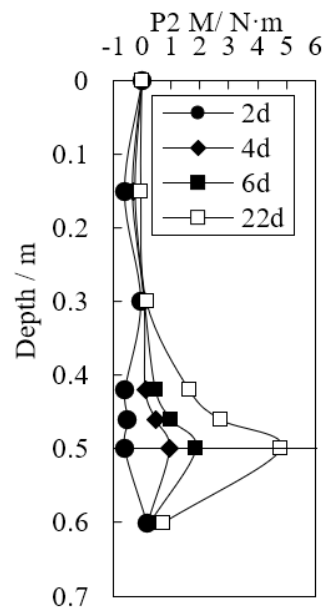

(a) $\theta=7^{\circ}$
P3 $\mathrm{M} / \mathrm{N} \cdot \mathrm{m}$

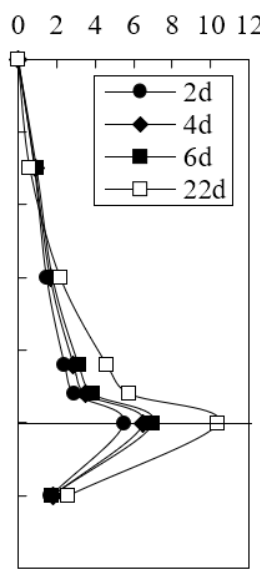

(b) $\theta=17^{\circ}$
Fig. 8 Variation of pile bending moment distribution with time

\section{Conclusion}

In this paper, indoor model tests were carried out to make long-term, uninterrupted measurements on rock-socketed inclined piles with different inclination angles. The variation rules of negative friction resistance and the bending moment of rock-socketed inclined piles under different consolidation time were obtained. The main conclusions are as follows:

(1) The settlement of the soil layer and the super pore pressure in soil increase and decrease with the accumulation of consolidation time, respectively, but the rate of change slows down from fast to stable gradually.

(2) In the consolidation process of the soil layer, the negative friction resistance, axial force and bending moment of piles gradually develop with the accumulation of consolidation time. The development speed in the early stage is faster than that in the later stage. When the load is applied to the soil surface, the neutral points are located at the rock-soil interface.

(3) With the addition of the inclination angle, the "downward pressure" effect of soil on the pile becomes more apparent. Hence, the bending moment of the pile body increases. The peak point of pile bending moment is always located at $0.9 \sim 1.0$ times soil depth.

The effect of negative skin friction of inclined pile on pile foundation is one of the important factors affecting the stability of inclined pile structure. There are surface loads on the soil layer in the model test, and the law may not be fully applicable to the soil layer without surface load. More experiments are needed to study in the future.

\section{Acknowledgments}

This work was supported by the National Natural Science Foundation of China (51878446, 52078336) and the Nature and Scientific Fund Project in Tianjin (18JCYBJC40500, 19JCYBJC22100) and the Tianjin Science and Technology Plan Project(20JCJQJC00220). 


\section{References}

1. Wu Shuangshuang, Hu Xinli, Zhang Han. Field test and calculation method research on negative skin friction of rock-socketed pile[J]. Rock and Soil Mechanics, 2019,40(9):1-8.

2. Li Lingling, Wang Lizhong, Xing Yuelong. Experimental research on negative skin friction of large-diameter bored piles[J]. Chinese Journal of Rock Mechanics and Engineering, 2009, 28(3): 583-590.

3. Indraratna B. Development of negative skin friction on driven piles in soft Bangkok clay: Reply[J]. Canadian Geotechnical Journal, 1993,30(5):890-891.

4. Ma Xuening, Fu Jiang, Wang Jun. Effect of different surcharge loading forms on negative skin friction of pile groups[J]. Rock and Soil Mechanics,2018, 39(10):33-40.

5. Yang Qing, Kong Gangqiang, Zheng Pengyi, et. Model test study of negative skin friction for single pile under surface load[J]. Rock and Soil Mechanics, 2008, 29(10):2805-2810.
6. Takahashi K. Bending of a batter pile due to ground settlement [J]. International Journal of Rock Mechanics and Mining resources and Geomechanics Abstracts, 1986,25(4):79-91.

7. Huang T, Zheng J, Gong W. The group effect on negative skin friction on piles[J]. Procedia Engineering, 2015,116:802-808.

8. Leung C F, Liao B K, Chow Y K. Behavior of pile subject to negative skin friction and axial load[J]. Journal of the Japanese Geotechnical Society Soils and Foundation, 2004,44(6):17-26.

9. Mehmet U E, Devrim S. Negative skin friction from surface settlement measurements in model group tests[J]. Canadian Geotechnical Journal, 1995, 32: 1075-1079.

10. Shibata T, Sekiguchi H, Yukitomo H. Model test and analysis of negative friction acting on piles[J]. Soils and Foundations, 1982,22(2):29-39.

11. Yan Shuwang, Lang Ruiqing, Sun Liqiang. Experimental study on negative skin friction of piles under low location vacuum preloading[J]. Journal of Southeast University (Natural Science Edition), 2016, 43: 184-189. 